\title{
Risks and neurological benefits of meningioma surgery in elderly patients compared to young patients
}

\author{
Hajrullah Ahmeti ${ }^{1}$ (1) Christoph Borzikowsky ${ }^{2} \cdot$ Dieter Hollander $^{3} \cdot$ Christoph Röcken $^{4} \cdot$ Olav Jansen $^{5}$. \\ Michael Synowitz ${ }^{1}$ Maximilian H. Mehdorn ${ }^{1}$
}

Received: 13 July 2021 / Accepted: 16 August 2021 / Published online: 1 September 2021

(c) The Author(s) 2021

\begin{abstract}
Introduction While surgery is the primary treatment choice for intracranial meningiomas in young patients, surgery in elderly patients, especially those with pre-existing comorbidities, has been the subject of repeated discussion. This study investigated the postoperative risks and neurological benefits of meningioma surgery in elderly patients compared to young patients.

Methods In total, 768 patients were included and divided into two main groups: group I (age: $\leq 64$ years; 484 young patients) and group II (age: $\geq 65$ years; 284 elderly patients). Group II was subdivided into: IIa (age: 65-69 years), IIb (age: 70-79 years); and IIc (age: $\geq 80$ years).

Results The total tumor resection rate was higher in the elderly cohort than in the young cohort $(84.5$ and $76.2 \%$, respectively). 154 young patients (31.8\%) and 132 elderly patients (46.5\%) developed postoperative morbidities, with the three most common being bleeding (12.9\%), cranial nerve disorder (10\%) and CSF fistula (8.1\%). Postoperative bleeding, palsy, speech disorder, pneumonia and renal insufficiency were dependent on age $(r=0.123, p=0.001 ; r=0.089, p=0.014 ; r=0.100$, $p=0.006 ; r=0.098, p=0.007$ and $r=0.084, p=0.020$ ) and presented more often in elderly patients. 6 young and 15 elderly patients died during the 17.4-year observation period. Most patients showed a significant improvement in postoperative KPS $(p<0.001)$, except those over 80 years old $(p=0.753)$. The KPS at the last follow-up was significantly improved in all patients $(\mathrm{p}<0.001)$.

Conclusion Meningioma surgery is associated with a higher rate of postoperative complications in elderly patients than in young patients. Most elderly patients, similar to young patients, show a significant improvement in neurological status postoperatively.
\end{abstract}

Keywords Elderly patients $\cdot$ Comorbidities $\cdot$ Intracranial meningiomas $\cdot$ Operative risks $\cdot$ Meningioma surgery . Neurological conditions

Hajrullah Ahmeti

Hajrullah.Ahmeti@uksh.de

1 Department of Neurosurgery, University Hospital Schleswig-Holstein, Campus Kiel, Arnold-Heller-Str. 3, 24105 Kiel, Germany

2 Institute of Medical Informatics und Statistics, University Hospital Schleswig-Holstein, Kiel University, Kiel, Germany

3 Department of Anesthesiology, University Hospital Schleswig-Holstein, Campus Kiel, Kiel, Germany

4 Department of Pathology, University Hospital Schleswig-Holstein, Campus Kiel, Kiel, Germany

5 Department of Radiology and Neuroradiology, University Hospital Schleswig-Holstein, Campus Kiel, Kiel, Germany

\section{Introduction}

Meningiomas are the most common primary brain tumors in adults. According to the Central Brain Tumor Registry of the United States of America (CBTRUS), meningiomas account for $38.3 \%$ of all primary brain tumors [1]. The treatment of choice in meningiomas is surgery [2]. It is well known that meningiomas are more common in elderly patients than in young patients [2-4]. The incidence rate of intracranial meningiomas increases dramatically with age. Patients between the ages of 20 and 34 years have an incidence rate for meningiomas of $1.46 / 100,000$. This number increases to $29.08 / 100,000$ in patients between the ages of 65 and 74 years and to $55.08 / 100,000$ in patients over 85 years old [1]. In particular, elderly patients often have high rates of comorbidities, 
which suggests a high perioperative risk. Increased morbidity and mortality after meningioma surgery in elderly patients have been reported in many studies [2, 5-8]. Therefore, a 'wait and see' strategy, especially in patients with comorbidities and few symptomatic tumors, might be preferred. However, Arienta et al. showed a significantly increased tumor-related risk of morbidity and mortality in their 'wait and see' group [9]. In addition, atypical and anaplastic meningiomas, which behave more aggressively than benign meningiomas, seem to occur more often in elderly patients and could complicate the clinical course $[1,2,10]$.

Most presented patient series on this subject have a small number of elderly patients. In the present study, with a large representative series, we evaluated the postoperative risk and neurological benefits of meningioma surgery in elderly patients in different age groups compared to young patients.

\section{Methods}

In this retrospective study, all patients who underwent primary surgery for intracranial meningioma in our department between 2003 and 2019 were included. Patients who received conservative therapy and those with recurrent meningiomas were excluded from the study. The patients were divided into two groups: group I (aged $\leq 64$ years) and group II (aged $\geq 65$ years). Furthermore, group II was divided into three subgroups: IIa (aged 65-69 years); IIb aged 70-79 years) and IIc (aged over 80 years). Group I was regarded as the control group (young patients).

The patients were operated on by different neurosurgeons with the intention of maximal safe feasible tumor resection. All patients were monitored postoperatively in our neurosurgical intensive care unit and were examined neurologically by a neurosurgeon. The diagnosis of meningioma was confirmed histologically according to WHO criteria $[11,12]$.

All patient's demographics and characteristics, comorbidities, tumor and treatment characteristics, neurological status according to the KPS [14] preoperatively, postoperatively and at the time of last follow-up, ASA score according to the American Society of Anesthesiologists score [13], postoperative complications within 30 days and new neurological deficits, and follow-up data were collected by using medical inpatient and outpatient records of our department. Depending on the size, site and vascularization, tumor complexity was classified as uncritical, moderately critical and critical by an experienced neurosurgeon.

\section{Statistics}

All statistical analyses were carried out with IBM SPSS Statistics for Windows [15]. The following statistical analyses have been conducted: Absolute and relative frequencies, mean and standard deviation (SD), median and range of values, Spearman's rank correlation coefficients, Chi-squared $\left(\chi^{2}\right)$, Fisher's exact tests, two-sample t-tests, multiple logistic and multiple linear regression analyses, unstandardized and standardized regression coefficients, $95 \%$ confidence intervals, $\mathrm{p}$-values and odds ratios (ORs). p-Values $<0.05$ were regarded as statistically significant.

\section{Results}

\section{General characteristics}

In this study, 768 patients (484 young and 284 elderly patients) were included (Table 1). The three most common tumor sites were convexity (28.8\%), sphenoid ridge (20.1\%) and falx/parasagittal (15.2\%). In all, 62 patients (8.1\%) had multilocular meningiomas as follows: 37 patients $(7.6 \%)$ in group I and 25 patients (8.8\%) in group II, namely. The extent of edema showed a significant correlation with the size of the tumor in young (group I) and elderly patients (group II), and the larger the tumor was, the more extensive the edema (group I: $\mathrm{r}=0.468, \mathrm{p}<0.001$; group II: $\mathrm{r}=0.410$, $\mathrm{p}<0.001)$. In the subgroups, only subgroup IIc did not show a correlation between tumor size and edema (IIa: $r=0.623$, $\mathrm{p}<0.001$; IIb: $\mathrm{r}=0.333, \mathrm{p}=0.001$; IIc: $\mathrm{r}=0.101, \mathrm{p}=0.576$ ).

\section{Symptoms, neurological conditions and comorbidities}

The young patients more often suffered than elderly patients from cranial nerve disorder (nerve II-XII) $(\mathrm{p}<0.001)$ and headache $(\mathrm{p}<0.001)$. On the other hand, the elderly patients more often had gait disorders and dizziness $(\mathrm{p}<0.001)$ and personality changes and memory disorders $(p<0.001$; Table 2). The larger the tumor was, the more frequently personality change and memory disorder $(r=0.228, p<0.001)$, palsy $(\mathrm{r}=0.201, \mathrm{p}<0.001)$, speech disorder $(\mathrm{r}=0.146$, $\mathrm{p}=0.001)$, seizure $(\mathrm{r}=0.096, \mathrm{p}=0.024)$, olfactory dysfunction $(r=0.089, p=0.038)$ and cranial nerve disorder (nerve II-XII) $(r=0.097, p=0.023)$ occurred.

The mean preoperative KPS was $79.90 \mathrm{SD} \pm 12.31$ (range 20-100) in the entire cohort. The young patients showed a mean preoperative KPS of 81.44 ( $\mathrm{SD} \pm 11.11)$, and the elderly patients showed a mean preoperative KPS of 77.28 $(\mathrm{SD} \pm 13.74)$; the results for subgroups IIa, IIb, and IIc were $79.89(\mathrm{SD} \pm 11.70), 77.76(\mathrm{SD} \pm 14.50)$ and 70.48 ( $\mathrm{SD} \pm 14.13)$, respectively (Fig. 1; Supplemental Content).

Thirty-two patients $(4.2 \%)$ had different neurosurgical interventions in their medical history, most often spine surgery. With the exception of depression, which was more common in the young patients (group I vs. II: 28 patients $(5.8 \%)$ vs. 4 patients $(1.4 \%),(p=0.002))$, all other 
Table 1 General patient characteristics

\begin{tabular}{|c|c|c|c|c|c|c|c|c|c|c|c|c|}
\hline \multirow[t]{2}{*}{ General characteristics } & \multicolumn{2}{|c|}{ All patients } & \multicolumn{2}{|c|}{$\begin{array}{l}\text { Group } \\
\text { I (age: } \leq \\
64 \text { yrs) }\end{array}$} & \multicolumn{2}{|c|}{$\begin{array}{l}\text { Group } \\
\text { II (age: } \geq \\
65 \text { yrs) }\end{array}$} & \multicolumn{2}{|c|}{$\begin{array}{l}\text { Subgroup } \\
\text { IIa (age: } \\
65-69 \text { yrs) }\end{array}$} & \multicolumn{2}{|c|}{$\begin{array}{l}\text { Subgroup } \\
\text { IIb (age: } \\
70-79 \text { yrs) }\end{array}$} & \multicolumn{2}{|c|}{$\begin{array}{l}\text { Subgroup } \\
\text { IIc (age: } \geq \\
80 \text { yrs) }\end{array}$} \\
\hline & No. & $\%$ & No. & $\%$ & No. & $\%$ & No. & $\%$ & No. & $\%$ & No. & $\%$ \\
\hline No. of patients & 768 & 100 & 484 & 63 & 284 & 37 & 101 & 13.1 & 142 & 18.7 & 41 & 5.3 \\
\hline Age (median) & 60 & - & 53 & - & 72 & - & 67 & - & 73 & - & 83 & - \\
\hline \multicolumn{13}{|l|}{ Sex } \\
\hline Female & 579 & 75.4 & 376 & 77.7 & 203 & 71.5 & 70 & 69.3 & 102 & 71.5 & 31 & 75.6 \\
\hline Male & 189 & 24.6 & 108 & 22.3 & 81 & 28.5 & 31 & 30.7 & 40 & 28.5 & 10 & 24.4 \\
\hline \multicolumn{13}{|l|}{ Tumor size } \\
\hline $1-3 \mathrm{~cm}$ & 252 & 32.8 & 170 & 35.1 & 82 & 28.9 & 35 & 34.7 & 36 & 25 & 11 & 26.8 \\
\hline $3-6 \mathrm{~cm}$ & 233 & 30.3 & 137 & 28.3 & 96 & 33.8 & 24 & 23.8 & 57 & 39.6 & 16 & 39 \\
\hline $6-10 \mathrm{~cm}$ & 61 & 7.9 & 37 & 7.6 & 24 & 8.5 & 6 & 5.9 & 12 & 8.3 & 6 & 14.6 \\
\hline $10-15 \mathrm{~cm}$ & 3 & 0.4 & 2 & 0.4 & 1 & 0.4 & - & - & 1 & 0.7 & - & - \\
\hline$>20 \mathrm{~cm}$ & 1 & 0.1 & - & - & 1 & 0.4 & - & - & - & - & 1 & 2.4 \\
\hline NK & 218 & 28.4 & 138 & 28.5 & 80 & 28.2 & 36 & 35.6 & 38 & 26.4 & 7 & 17.1 \\
\hline \multicolumn{13}{|l|}{ Brain edema } \\
\hline None & 380 & 49.5 & 259 & 53.5 & 121 & 42.6 & 53 & 52.5 & 62 & 43.1 & 7 & 17.1 \\
\hline Moderate & 190 & 24.7 & 113 & 23.3 & 77 & 27.1 & 20 & 19.8 & 39 & 27.1 & 19 & 46.3 \\
\hline Large & 148 & 19.3 & 75 & 15.5 & 73 & 25.7 & 20 & 19.8 & 39 & 27.1 & 14 & 34.1 \\
\hline NK & 50 & 6.5 & 37 & 7.6 & 13 & 4.6 & 8 & 7.9 & 4 & 2.8 & 1 & 2.4 \\
\hline Asymptomatic meningioma & 73 & 9.5 & 50 & 10.3 & 23 & 8.1 & 11 & 10.9 & 13 & 9 & - & - \\
\hline
\end{tabular}

NKnot known, yrs years comorbidities showed an increasing incidence with age (Table 2).

\section{Surgery, histology, postoperative morbidity, and mortality}

Total tumor resection was achieved in 609 patients (79.3\%; Table 3$)$. In the young patients but not in the elderly patients (group II, $\mathrm{p}=0.345$ ), the extent of tumor resection was significantly dependent on tumor size (group I: $r=0.148$, $\mathrm{p}=0.007)$. Postoperatively, 154 patients $(31.8 \%)$ in the young cohort and 132 patients (46.5\%) in the elderly cohort developed morbidities (Table 3). Postoperative bleeding, palsy, speech disorder, pneumonia and renal insufficiency depended on age $(r=0.123, p=0.001 ; r=0.089, p=0.014$; $\mathrm{r}=0.100, \mathrm{p}=0.006 ; \mathrm{r}=0.098, \mathrm{p}=0.007$ and $\mathrm{r}=0.084$, $\mathrm{p}=0.020)$ and were presented more often in elderly patients (Table 3 ). In elderly patients, males were more frequently affected by bleeding than females $(r=0.122, p=0.001)$.

Tumor size correlated with the occurrence of bleeding $(r=0.186, p<0.001)$, seizures $(r=0.133, p=0.002)$, CSF fistulas $(r=0.95, p=0.027)$, delirium $(r=0.102, p=0.017)$ and pneumonia $(r=0.122, p=0.004)$. In addition, the complexity of the tumor also correlated with the risk of bleeding $(\mathrm{r}=0.136, \mathrm{p}<0.001)$, cranial nerve disorder $(\mathrm{r}=0.165$, $\mathrm{p}<0.001)$ and CSF fistula $(\mathrm{r}=0.132, \mathrm{p}<0.001)$ in young and elderly patients. Tumor site did not have any effect on postoperative morbidity or mortality. On the other hand, the extent of edema indicated a significant risk for bleeding $(\mathrm{r}=0.165, \mathrm{p}<0.001)$, palsy $(\mathrm{r}=0.076, \mathrm{p}=0.042)$, cranial nerve disorder $(\mathrm{r}=0.101, \mathrm{p}=0.007)$, ischemic infarction $(r=0.110, p=0.003)$, delirium $(r=0.108, p=0.004)$, speech disorder $(r=0.103, p=0.006)$ and pneumonia $(r=0.076$, $\mathrm{p}=0.041)$. The extent of tumor resection showed a significant effect on the occurrence of cranial nerve disorder in the young cohort $(r=0.186, p<0.001)$ and in subgroup IIb $(\mathrm{r}=0.178, \mathrm{p}=0.38)$. Some particular postoperative morbidities were more frequently observed when the following comorbidities were present: arterial hypertension, heart failure/arrhythmia, renal failure and depression. Arterial hypertension and heart failure/arrhythmia showed a high risk for seizures $(r=0.094, p=0.009 ; r=0.122, p=0.001)$ and speech disorder $(\mathrm{r}=0.109, \mathrm{p}=0.003 ; \mathrm{r}=0.113, \mathrm{p}=0.002)$ and depression for respiratory failure $(r=0.117, p=0.001)$. Additionally, heart failure/arrhythmia indicated a significantly higher incidence of bleeding $(r=0.190, p<0.001)$. An increased risk for developing postoperative bleeding in patients treated with perioperative anticoagulant drugs was observed in the entire cohort $(r=0.089, \mathrm{p}=0.013)$ but not in the young (group I: $r=0.012, p=0.792$ ) or elderly cohorts (group II: $r=0.086, p=0.147$ ).

Multiple logistic regression analysis showed a significant impact of brain edema ( $\mathrm{OR}=2.34,95 \%$ CI [1.36; 4.03], $\mathrm{p}=0.002)$, sex $(\mathrm{OR}=0.30,95 \%$ CI $[0.12 ; 0.72], \mathrm{p}=0.008)$ 
Table 2 Symptoms, neurological conditions, comorbidities and ASA score

\begin{tabular}{|c|c|c|c|c|c|c|c|c|c|c|c|c|}
\hline \multirow[t]{2}{*}{ Symptoms/neurological conditions and comorbidities } & \multicolumn{2}{|c|}{ All patients } & \multicolumn{2}{|c|}{$\begin{array}{l}\text { Group I (age: } \\
\leq 64 \text { yrs) }\end{array}$} & \multicolumn{2}{|c|}{$\begin{array}{l}\text { Group } \\
\text { II (age: } \geq 65 \\
\text { yrs) }\end{array}$} & \multicolumn{2}{|c|}{$\begin{array}{l}\text { Subgroup } \\
\text { IIa (age: } \\
65-69 \text { yrs) }\end{array}$} & \multicolumn{2}{|c|}{$\begin{array}{l}\text { Subgroup } \\
\text { IIb (age: } \\
70-79 \text { yrs) }\end{array}$} & \multicolumn{2}{|c|}{$\begin{array}{l}\text { Subgroup } \\
\text { IIc (age: } \geq \\
80 \text { yrs) }\end{array}$} \\
\hline & No. & $\%$ & No. & $\%$ & No. & $\%$ & No. & $\%$ & No. & $\%$ & No. & $\%$ \\
\hline \multicolumn{13}{|l|}{ Symptoms/neurological conditions } \\
\hline Cranial nerve disorder & 237 & 30.9 & 171 & 35.3 & 66 & 23.2 & 25 & 24.8 & 30 & 20.8 & 11 & 26.8 \\
\hline Headache & 229 & 29.8 & 168 & 34.7 & 61 & 21.5 & 26 & 25.7 & 31 & 21.5 & 4 & 9.8 \\
\hline Gait disorder and dizziness & 148 & 19.3 & 73 & 15.1 & 75 & 26.4 & 24 & 23.8 & 37 & 25.7 & 15 & 36.6 \\
\hline Seizure & 106 & 13.8 & 66 & 13.6 & 40 & 14.1 & 10 & 9.9 & 20 & 13.9 & 10 & 24.4 \\
\hline Personality change and memory disorder & 104 & 13.5 & 49 & 10.1 & 55 & 19.4 & 17 & 16.8 & 27 & 18.8 & 11 & 26.8 \\
\hline Palsy & 62 & 8.1 & 28 & 5.8 & 34 & 12 & 5 & 5 & 21 & 14.6 & 8 & 19.5 \\
\hline Sensitive disorder & 45 & 5.9 & 29 & 6 & 16 & 5.6 & 4 & 4 & 11 & 7.6 & 1 & 2.4 \\
\hline Speech disorder & 43 & 5.6 & 20 & 4.1 & 23 & 8.1 & 9 & 8.6 & 8 & 5.6 & 6 & 14.6 \\
\hline Swelling & 34 & 4.4 & 30 & 6.2 & 4 & 1.4 & 1 & 1 & 3 & 2.1 & - & - \\
\hline Olfactory dysfunction & 28 & 3.6 & 17 & 3.5 & 11 & 3.9 & 6 & 5.9 & 5 & 3.5 & - & - \\
\hline Hormonal disorder & 5 & 0.7 & 5 & 1 & - & - & - & - & - & - & - & - \\
\hline \multicolumn{13}{|l|}{ Comorbidities } \\
\hline Arterial hypertension & 323 & 42.1 & 147 & 30.4 & 176 & 62 & 48 & 47.5 & 97 & 67.4 & 33 & 80.5 \\
\hline Heart failure/arrhythmia & 74 & 9.6 & 18 & 3.7 & 56 & 19.7 & 12 & 11.9 & 30 & 20.8 & 14 & 34.1 \\
\hline Heart anomaly & 23 & 3 & 9 & 1.9 & 14 & 4.9 & 4 & 4 & 6 & 4.2 & 4 & 9.8 \\
\hline Diabetes mellitus & 74 & 9.6 & 31 & 6.4 & 43 & 15.1 & 13 & 12.9 & 26 & 18.1 & 5 & 12.2 \\
\hline COPD/asthma & 48 & 6.3 & 21 & 4.3 & 27 & 9.5 & 4 & 4 & 19 & 13.2 & 4 & 9.8 \\
\hline Any cancers & 115 & 15 & 60 & 12.4 & 55 & 19.4 & 13 & 12.9 & 30 & 20.8 & 12 & 29.3 \\
\hline Renal failure & 23 & 3 & 8 & 1.7 & 15 & 5.3 & 2 & 2 & 9 & 6.3 & 4 & 9.8 \\
\hline Endocrine disease & 120 & 15.6 & 73 & 15.1 & 47 & 16.5 & 10 & 9.9 & 30 & 20.8 & 8 & 19.5 \\
\hline Depression & 32 & 4.2 & 28 & 5.8 & 4 & 1.4 & 2 & 2 & 2 & 1.4 & - & - \\
\hline Neurosurgical intervention & 32 & 4.2 & 19 & 3.9 & 13 & 4.6 & 7 & 6.9 & 4 & 2.8 & 2 & 4.9 \\
\hline Other diseases ${ }^{\mathrm{a}}$ & 286 & 37.2 & 147 & 30.4 & 139 & 48.9 & 42 & 41.6 & 72 & 50 & 26 & 63.4 \\
\hline No comorbidity & 210 & 27.3 & 173 & 35.7 & 37 & 13 & 20 & 19.8 & 16 & 11.1 & 1 & 2.4 \\
\hline Anticoagulant & 102 & 13.3 & 26 & 5.4 & 76 & 26.8 & 20 & 19.8 & 44 & 30.6 & 13 & 32.7 \\
\hline \multicolumn{13}{|l|}{ ASA score } \\
\hline 1 & 114 & 14.8 & 95 & 19.6 & 19 & 6.7 & 7 & 6.9 & 12 & 8.3 & - & - \\
\hline 2 & 435 & 56.6 & 304 & 62.8 & 131 & 46.1 & 57 & 56.4 & 59 & 41 & 17 & 41.5 \\
\hline 3 & 191 & 24.9 & 69 & 14.3 & 122 & 43 & 35 & 34.7 & 66 & 45.8 & 21 & 51.2 \\
\hline 4 & 16 & 2.1 & 8 & 1.7 & 8 & 2.8 & - & - & 5 & 3.5 & 3 & 7.3 \\
\hline 5 & 2 & 0.3 & 2 & 0.4 & - & - & - & - & - & - & - & - \\
\hline
\end{tabular}

yrs years

${ }^{a}$ Other diseases represent different diseases, such as allergies, peripheral arterial disease, musculoskeletal diseases and different surgical interventions

and WHO classification of tumors $(\mathrm{OR}=2.82,95 \% \mathrm{CI}$ $[1.17 ; 6.76], \mathrm{p}=0.020$ ) on postoperative bleeding in elderly patients and of tumor size $(\mathrm{OR}=2.09,95 \% \mathrm{CI}[1.06 ; 4.10]$, $\mathrm{p}=0.032$ ) on postoperative bleeding in young patients. The extent of tumor resection $(\mathrm{OR}=2.01,95 \%$ CI $[1.22 ; 3.31]$, $\mathrm{p}=0.006)$ in elderly patients and the complexity of the tumor $(\mathrm{OR}=2.43,95 \% \mathrm{CI}[1.16 ; 5.07], \mathrm{p}=0.018)$ and brain edema $(\mathrm{OR}=0.5,95 \% \mathrm{CI}[0.27 ; 0.93], \mathrm{p}=0.029)$ in young patients had a significant influence on postoperative cranial nerve (II-XII) disorder. CSF fistula was significantly affected by the complexity of the tumor $(\mathrm{OR}=11.63,95 \% \mathrm{CI}[1.24$; 109.01], $\mathrm{p}=0.032$ ) in elderly patients. Postoperative seizures were significantly influenced by tumor size $(\mathrm{OR}=4.28,95 \%$ CI $[1.76 ; 10.38], p=0.001)$ in elderly patients and by the complexity of the tumor $(\mathrm{OR}=0.25,95 \%$ CI $[0.07 ; 0.89]$, $\mathrm{p}=0.032$ ) in young patients.

The mean postoperative KPS was $83.47(\mathrm{SD} \pm 15.46)$ (range 0-100) in the entire cohort. The young patients had a mean postoperative KPS of $85.36(\mathrm{SD} \pm 12.29)$, and of the elderly patients, the mean postoperative KPS was 80.21 

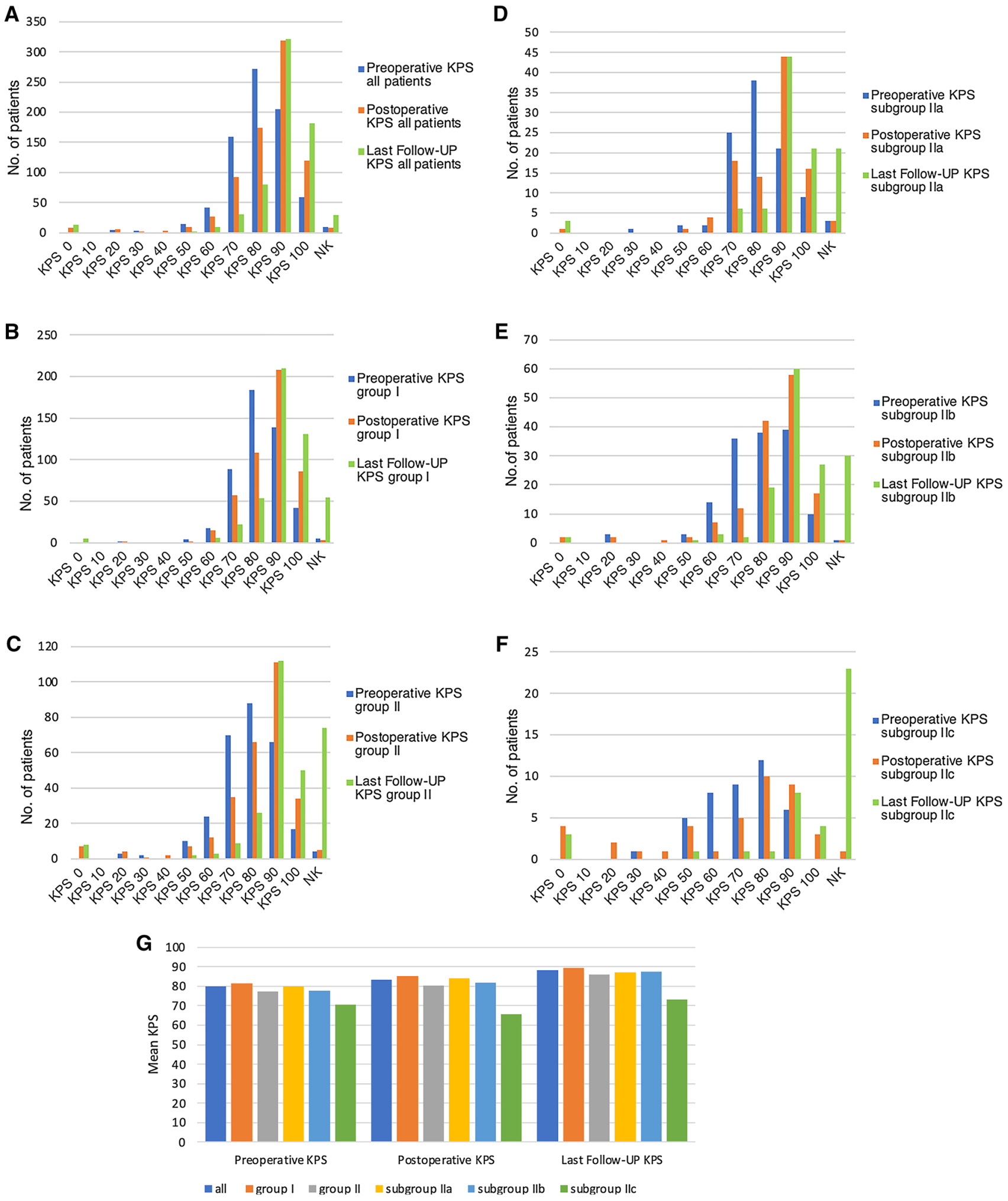

Fig. 1 Preoperative, postoperative and last follow-up Karnofsky Performance Status Scale (KPS) (A-G). NK not known

( $\mathrm{SD} \pm 19.35)$. With increasing age, the mean postoperative KPS was lower (subgroup: IIa 83.98 (SD \pm 14.34 ), IIb $81.95(\mathrm{SD} \pm 16.66)$ and IIc $65.75(\mathrm{SD} \pm 30.11)$ ) (Fig. 1;
Supplemental Content). Advancing age had a significant effect on postoperative KPS only in patients over 80 years old $(\mathrm{p}=0.004)$. The entire cohort, groups I and II and 
subgroups IIa and IIb showed a significant improvement in the postoperative KPS compared to the preoperative KPS $(\mathrm{p}<0.001)$; in contrast, subgroup IIc showed a deterioration of postoperative KPS.

At the time of the last follow-up, all patients showed a significant improvement in KPS (entire cohort: 88.15 ( $\mathrm{SD} \pm 15.60)$; group I: 89.18 ( $\mathrm{SD} \pm 13.27)$; group II: 86.04 ( $\mathrm{SD} \pm 19.39$ ); subgroups: IIa 87 (SD \pm 19.05$)$, IIb 87.63 $(\mathrm{SD} \pm 14.95)$ and $\mathrm{IIc} 73.33(\mathrm{SD} \pm 35.81)$ ), also compared to the postoperative KPS ( $p<0.001$; Fig. 1; Supplemental Content). At the time of the last follow-up, 54 patients showed deterioration in KPS compared to the postoperative KPS (26 patients $(3.4 \%)$ tumor-related; 15 patients $(2 \%)$ tumorunrelated; 13 patients $(1.7 \%)$ by pain or hypoesthesia in the surgical scar area).

The postoperative KPS and the KPS at the last follow-up correlated significantly with the preoperative KPS $(r=0.681$, $\mathrm{p}<0.001$ and $\mathrm{r}=0.346, \mathrm{p}<0.001)$. The extent of tumor resection affected the postoperative KPS and the KPS at the last follow-up only in the young cohort; the higher the resection rate was, the higher the postoperative KPS and the KPS at the last follow-up (group I: $r=0.225, \mathrm{p}<0.001$ and $r=0.243, p<0.001$ ). The postoperative KPS was also dependent on tumor size only in the young cohort (group I: $r=0.207, p<0.001)$. On the other hand, tumor complexity and brain edema negatively influenced the postoperative KPS in young patients (group I: $r=0.335, p<0.001$ and $r=0.147, p=0.002$ ) and elderly patients (group II: $r=0.246, p=0.001$ and $r=0.191, p=0.002$ ). The KPS at the last follow-up was negatively affected by tumor complexity but not by brain edema (group I: $r=0.183, p<0.001$; $\mathrm{r}=0.012, \mathrm{p}=0.812$ and group II: $\mathrm{r}=0.175, \mathrm{p}=0.012$; $\mathrm{r}=0.092, \mathrm{p}<0.193)$.

The multiple linear regression analysis showed a significantly importance of preoperative KPS $(b=0.66,95 \%$ CI $[0.47 ; 0.84], \beta=0.45, \mathrm{p}<0.001)$ and age $(\mathrm{b}=-0.49$, $95 \%$ CI $[-0.89 ;-0.09], \beta=-0.15, \mathrm{p}<0.016)$ on postoperative KPS in elderly patients, and of preoperative KPS $(b=0.49,95 \%$ CI $[0.41 ; 0.57], \beta=0.54, p<0.001)$, extent of tumor resection $(b=-1.63,95 \%$ CI $[-2.52 ;-0.74], \beta$ $=-0.17, \mathrm{p}<0.001)$, ASA score $(\mathrm{b}=-1.69,95 \% \mathrm{CI}[-2.94$; $-0.43], \beta=-0.11, p=0.008)$ and complexity of the tumor $(\mathrm{b}=-1.62,95 \%$ CI $[-2.95 ;-0.28], \beta=-0.11, \mathrm{p}<0.017)$ on postoperative KPS in young patients. The KPS at the last follow-up was significantly affected only by the ASA score $(\mathrm{b}=-8.06,95 \%$ CI $[-12.60 ;-3.53], \beta=-0.28, \mathrm{p}=0.001)$ in elderly patients and by the preoperative KPS $(b=0.3,95 \%$ CI $[0.17 ; 0.44], \beta=0.25, p<0.001)$ and extent of tumor resection $(b=-2.17,95 \%$ CI $[-3.52 ;-0.82], \beta=-0.17$, $\mathrm{p}=0.002)$ in young patients.

Twenty-one patients $(2.7 \%)$ died in an observation period of 17.4 years. Ten patients (1.3\%: $3(0.6 \%)$ young and 7
(2.5\%) elderly patients) experienced tumor-related death, and 11 patients $(1.4 \%: 3(0.6 \%)$ young and $8(2.8 \%)$ elderly patients) experienced non-tumor-related death. The highest mortality rate was in patients over 80 years of age ( 7 patients (17\%); Table 4).

Multiple logistic regression analysis showed a significant impact of the ASA score (OR $=9.29,95 \%$ CI [1.97; $43.62], p=0.005$ ) on mortality in elderly patients.

\section{Discussion}

Meningiomas are the most common primary intracranial tumors in adults [1]. While surgery is the first treatment of choice for young patients, this is the subject of repeated discussions for the treatment of elderly patients, especially for patients with pre-existing comorbidities. In recent decades, many studies have explored the risk of meningioma surgery in elderly patients. Most of these studies focused only on elderly patients without including control groups of young patients [16-18]. On the other hand, the series presented in the literature comparing meningioma surgery in elderly and young patients contains small numbers of elderly patients, most of whom included fewer than one hundred elderly patients [7, 19-22]. Bateman et al. presented the largest series of patients with intracranial meningiomas in 2304 elderly and 6557 young patients from a nationwide inpatient sample database [6]. However, this series does not provide data about the neurological status of the patients or the characteristics of each patient's tumor. We present here one of the largest single-center and representative series of 768 patients (484 young and 284 elderly patients) undergoing surgery for intracranial meningioma. To assess a particular age for a possible increased risk after meningioma surgery, the elderly cohort was subdivided into three subgroups, i.e., 65-69, 70-79, and over 80 years of age.

Most patients with intracranial meningiomas have tumor-related symptoms. In the literature, the number of asymptomatic patients in elderly and young cohorts ranges from 5 to $35.2 \%$ and 2 to $6.5 \%$, respectively $[18,19]$. In our cohort, only $9.5 \%$ of all the patients $(10.3 \%$ of the young and $8.1 \%$ of the elderly patients) were asymptomatic. Interestingly, all patients over 80 years old were symptomatic. The tumors in most of our asymptomatic patients were usually space-occupying tumors, unclear tumors or suspicion of other tumors, such as metastases, especially in elderly patients with known carcinomas.

Despite differences such as age, number of pre-existing diseases and ASA score, even in elderly patients, high total resection rates were achieved in $79-88.6 \%$ of elderly patients compared to $62.9-90.3 \%$ of young patients $[7,18$, 
Table 3 Surgery, histology, postoperative morbidity, mean and maximum follow-up

\begin{tabular}{|c|c|c|c|c|c|c|c|c|c|c|c|c|}
\hline \multirow[t]{2}{*}{ Surgery, histology, postoperative morbidity, follow-up } & \multicolumn{2}{|c|}{ All patients } & \multicolumn{2}{|c|}{$\begin{array}{l}\text { Group } \\
\text { I (age: } \leq 64 \\
\text { yrs) }\end{array}$} & \multicolumn{2}{|c|}{$\begin{array}{l}\text { Group } \\
\text { II (age: } \geq 65 \\
\text { yrs) }\end{array}$} & \multicolumn{2}{|c|}{$\begin{array}{l}\text { Subgroup } \\
\text { IIa (age: } \\
65-69 \text { yrs) }\end{array}$} & \multicolumn{2}{|c|}{$\begin{array}{l}\text { Subgroup } \\
\text { IIb (age: } \\
70-79 \text { yrs) }\end{array}$} & \multicolumn{2}{|c|}{$\begin{array}{l}\text { Subgroup } \\
\text { IIc (age: } \geq \\
80 \text { yrs) }\end{array}$} \\
\hline & No. & $\%$ & No. & $\%$ & No. & $\%$ & No. & $\%$ & No. & $\%$ & No. & $\%$ \\
\hline \multicolumn{13}{|l|}{ Simpson grade } \\
\hline I & 391 & 50.9 & 233 & 48.1 & 158 & 55.6 & 54 & 53.5 & 84 & 58.3 & 20 & 48.8 \\
\hline II & 218 & 28.4 & 136 & 28.1 & 82 & 28.9 & 35 & 34.7 & 35 & 24.3 & 13 & 31.7 \\
\hline III & 28 & 3.6 & 21 & 4.3 & 7 & 2.5 & 3 & 3 & 3 & 2.1 & 1 & 2.4 \\
\hline IV & 86 & 11.2 & 62 & 12.8 & 24 & 8.5 & 6 & 5.9 & 14 & 9.7 & 5 & 12.2 \\
\hline V & 7 & 0.9 & 6 & 1.2 & 1 & 0.4 & - & - & 1 & 0.7 & - & - \\
\hline NK & 38 & 4.9 & 26 & 5.4 & 12 & 4.2 & 3 & 3 & 7 & 4.9 & 2 & 4.9 \\
\hline \multicolumn{13}{|l|}{ WHO classification } \\
\hline I & 673 & 87.6 & 423 & 87.4 & 250 & 88 & 89 & 88.1 & 131 & 91 & 32 & 78 \\
\hline II & 67 & 8.7 & 46 & 9.5 & 21 & 7.4 & 9 & 8.9 & 6 & 4.2 & 6 & 14.6 \\
\hline III & 10 & 1.3 & 5 & 1 & 5 & 1.8 & 1 & 1 & 3 & 2.1 & 1 & 2.4 \\
\hline NK & 7 & 0.9 & 2 & 0.4 & 5 & 1.8 & 1 & 1 & 2 & 1.4 & 2 & 4.9 \\
\hline Mean Ki67-index & 5.8 & & 5.6 & & 6 & & 5.1 & & 5.9 & & 8.2 & \\
\hline Entire postoperative morbidity & 286 & 37.2 & 154 & 31.8 & 132 & 46.5 & 45 & 44.6 & 66 & 45.8 & 21 & 51.2 \\
\hline \multicolumn{13}{|l|}{ Postoperative morbidities } \\
\hline Bleeding & 99 & 12.9 & 44 & 9.1 & 55 & 19.4 & 16 & 15.8 & 27 & 18.8 & 12 & 29.3 \\
\hline Palsy & 25 & 3.3 & 8 & 1.7 & 17 & 6 & 6 & 5.9 & 8 & 5.6 & 3 & 7.3 \\
\hline Cranial nerve disorder & 77 & 10 & 49 & 10.1 & 28 & 9.9 & 11 & 10.9 & 15 & 10.4 & 2 & 4.9 \\
\hline CFS fistula & 62 & 8.1 & 37 & 7.6 & 25 & 8.8 & 11 & 10.9 & 12 & 8.3 & 2 & 4.9 \\
\hline Speech disorder & 20 & 2.6 & 5 & 1 & 15 & 5.3 & 6 & 5.9 & 6 & 4.2 & 3 & 7.3 \\
\hline Seizure & 29 & 3.8 & 14 & 2.9 & 15 & 5.3 & 5 & 5 & 5 & 3.5 & 5 & 12.2 \\
\hline Meningitis & 4 & 0.5 & 3 & 0.6 & 1 & 0.4 & - & - & 1 & 0.7 & - & - \\
\hline Delirium & 14 & 1.8 & 4 & 0.8 & 10 & 3.5 & 3 & 3 & 6 & 4.2 & 1 & 2.4 \\
\hline Hormonal disorder & 4 & 0.5 & 4 & 0.8 & - & - & - & - & - & - & - & - \\
\hline Ischemic infraction & 14 & 1.8 & 6 & 1.2 & 8 & 2.8 & 2 & 2 & 5 & 3.5 & 1 & 2.4 \\
\hline Vein thrombosis & 8 & 1 & 6 & 1.2 & 2 & 0.7 & - & - & 2 & 1.4 & - & - \\
\hline Pulmonary embolism & 4 & 0.5 & 1 & 0.2 & 3 & 1.1 & - & - & 2 & 1.4 & 1 & 2.4 \\
\hline Pneumonia & 11 & 1.4 & 3 & 0.6 & 8 & 2.8 & 1 & 1 & 4 & 2.8 & 3 & 7.3 \\
\hline Iatrogenic pneumothorax & 11 & 1.4 & 6 & 1.2 & 5 & 1.8 & 1 & 1 & 3 & 2.1 & 1 & 2.4 \\
\hline Respiratory insufficiency & 7 & 0.9 & 3 & 0.6 & 4 & 1.4 & - & - & 2 & 1.4 & 2 & 4.9 \\
\hline Renal insufficiency & 2 & 0.3 & - & - & 2 & 0.7 & - & - & - & - & 2 & 4.9 \\
\hline Heart attack & 1 & 0.1 & - & - & 1 & 0.4 & - & - & 1 & 0.7 & - & - \\
\hline Heart/circulatory failure & 7 & 0.9 & 3 & 0.6 & 4 & 1.4 & - & - & - & - & 4 & 2.8 \\
\hline Discharge to home & 586 & 76.3 & 394 & 81.4 & 192 & 67.6 & 77 & 76.2 & 98 & 68.1 & 18 & 43.9 \\
\hline Discharge to rehabilitation clinic or another department & 141 & 18.4 & 61 & 12.6 & 80 & 28.2 & 15 & 14.9 & 43 & 29.9 & 22 & 53.7 \\
\hline Mean follow-up in months & 40 & & 47 & & 28 & & 36 & & 26 & & 8 & \\
\hline Maximum follow-up in months & 215 & & 215 & & 155 & & 202 & & 132 & & 38 & \\
\hline
\end{tabular}

NK not known, yrs years

22, 23]. Li et al. reported a series of 70 patients over 65 years and 80 patients younger than 65 years with significantly low total resection rates of 50 and $68 \%$, respectively [21]. In our cohort, we achieved a total resection rate of $84.5 \%$ in elderly patients (group II) and $76.2 \%$ in young patients (group I). The total resection rate was also high in the subgroups, but it decreased with advancing age: subgroup IIa $88.2 \%$, IIb $82.6 \%$ and IIc $80.5 \%$. The extent of tumor resection in our young cohort depended significantly on tumor size $(r=0.148, p=0.007)$.

Morbidity after meningioma surgery has been reported in the literature for elderly and young patients at $7-69.6 \%$ and $8.8-57.5 \%$, respectively $[5-7,19,21]$. Postoperative morbidities in our cohort were within this range, i.e., $37.2 \%$, 
Table 4 Deceased patients

\begin{tabular}{|c|c|c|c|c|c|c|c|}
\hline Patient & Age (years) & Sex & Tumor site & Preoperative comorbidity & ASA score & Cause of death & Time of death \\
\hline 1 & 86 & f & Falx & $\begin{array}{l}\text { Arterial hypertension, } \\
\text { heart arrhythmia, antico- } \\
\text { agulant drug }\end{array}$ & 3 & Bleeding & 4 days \\
\hline 2 & 92 & $\mathrm{f}$ & Sphenoid ridge & Renal insufficiency & 3 & Multiple organ failure & 4 days \\
\hline 3 & 79 & $\mathrm{~m}$ & Sphenoid ridge & $\begin{array}{l}\text { Arterial hypertension, dia- } \\
\text { betes mellitus, cancer }\end{array}$ & 4 & $\begin{array}{l}\text { Subarachnoidal hemor- } \\
\text { rhage (incidental menin- } \\
\text { gioma) }\end{array}$ & 10 days \\
\hline 4 & 88 & f & Falx & $\begin{array}{l}\text { Arterial hypertension, } \\
\text { heart insufficiency, anti- } \\
\text { coagulant drug }\end{array}$ & 3 & seizure & 12 days \\
\hline 5 & 80 & $\mathrm{~m}$ & Falx & $\begin{array}{l}\text { Arterial hypertension, } \\
\text { heart insufficiency, anti- } \\
\text { coagulant drug }\end{array}$ & 2 & $\begin{array}{l}\text { Bleeding, multiple organ } \\
\text { failure }\end{array}$ & 14 days \\
\hline 6 & 72 & $\mathrm{~m}$ & Falx & $\begin{array}{l}\text { Arterial hypertension, } \\
\text { heart attack, heart insuf- } \\
\text { ficiency, COPD }\end{array}$ & 3 & Heart failure pneumonia & 15 days \\
\hline 7 & 66 & $\mathrm{~m}$ & Sphenoid ridge & $\begin{array}{l}\text { Arterial hypertension, } \\
\text { heart attack, peripheral } \\
\text { arterial disease, antico- } \\
\text { agulant drug }\end{array}$ & 3 & Bleeding & 20 days \\
\hline 8 & 45 & $\mathrm{f}$ & Sphenoid ridge & - & 2 & Bleeding & 23 days \\
\hline 9 & 76 & $\mathrm{f}$ & Convexity & $\begin{array}{l}\text { Arterial hypertension, } \\
\text { heart insufficiency, } \\
\text { COPD, depression, renal } \\
\text { cell carcinoma }\end{array}$ & 3 & $\begin{array}{l}\text { Pneumonia and heart } \\
\text { insufficiency }\end{array}$ & 38 days \\
\hline 10 & 86 & $\mathrm{f}$ & Tentorium & - & 2 & $\begin{array}{l}\text { Recurrence of atypical } \\
\text { meningioma with intrac- } \\
\text { erebral bleeding }\end{array}$ & 4 months \\
\hline 11 & 83 & $\mathrm{f}$ & Tuberculum sellae & $\begin{array}{l}\text { Arterial hypertension, } \\
\text { anticoagulant drug }\end{array}$ & 4 & Stroke & 5 months \\
\hline 12 & 29 & $\mathrm{~m}$ & Convexity & - & 3 & $\begin{array}{l}\text { Recurrence of anaplastic } \\
\text { meningioma with intrac- } \\
\text { erebral bleeding }\end{array}$ & 11 months \\
\hline 13 & 87 & $\mathrm{f}$ & Falx & $\begin{array}{l}\text { Arterial hypertension, } \\
\text { heart anomaly }\end{array}$ & 3 & Intraventricular bleeding & 13 months \\
\hline 14 & 68 & $\mathrm{f}$ & Tuberculum sellae & $\begin{array}{l}\text { Arterial hypertension, } \\
\text { anticoagulant drug }\end{array}$ & 3 & Pulmonary embolism & 24 months \\
\hline 15 & 54 & $\mathrm{~m}$ & Intraventricular & $\begin{array}{l}\text { Heart transplant, arte- } \\
\text { rial hypertension, heart } \\
\text { anomaly }\end{array}$ & 3 & Heart failure & 4 years \\
\hline 16 & 51 & $\mathrm{~m}$ & Olfactory groove & $\begin{array}{l}\text { Arterial hypertension, } \\
\text { diabetes mellitus, depres- } \\
\text { sion }\end{array}$ & 2 & Heart failure & 6 years and 3 months \\
\hline 17 & 74 & $\mathrm{f}$ & Cerebellopontine angle & $\begin{array}{l}\text { Heart insufficiency, diabe- } \\
\text { tes mellitus, anticoagu- } \\
\text { lant drug }\end{array}$ & 3 & $\begin{array}{l}\text { Sepsis after aspiration } \\
\text { pneumonia }\end{array}$ & 7 years and 8 months \\
\hline 18 & 68 & $\mathrm{~m}$ & Sphenoid ridge & - & 3 & Stroke & 10.10 years \\
\hline 19 & 65 & $\mathrm{f}$ & Convexity & Asthma, heart insufficiency & 3 & Acute subdural hematoma & 12 years \\
\hline 20 & 47 & $\mathrm{~m}$ & Sphenoid ridge & - & 2 & $\begin{array}{l}\text { Recurrence of atypical } \\
\text { meningioma }\end{array}$ & 12.9 years \\
\hline 21 & 61 & $\mathrm{f}$ & Cerebellopontine angle & $\begin{array}{l}\text { Arterial hypertension, can- } \\
\text { cer, endocrine disease }\end{array}$ & 3 & $\begin{array}{l}\text { Pneumonia after surgery } \\
\text { of femur fracture }\end{array}$ & 12.9 years \\
\hline
\end{tabular}

COPD chronic obstructive pulmonary disease 
and was more common in elderly patients $(46.5 \%$ in group II vs. $31.8 \%$ in group I). The three most common postoperative morbidities in the entire cohort were bleeding (12.9\%), cranial nerve disorder (10\%), and CSF fistula (8.1\%). Postoperative bleeding, palsy, speech disorder, pneumonia and renal insufficiency were present more often in elderly patients. Patients over 80 years old had the highest bleeding rate $(29.3 \%)$, and young patients had the lowest bleeding rate $(9.1 \%)$. In elderly patients, males were more frequently affected by bleeding than females $(r=0.122, p=0.001)$. Maurice-Williams and Kitchen reported a bleeding rate of $20 \%$ for elderly patients and no bleeding in young patients [24]. Cranial nerve disorder is one of the most common surgery-related complications reported in the literature [18, 21]. Postoperative bleeding, infections and deep vein thromboses were the three most common complications in elderly patients reported by Boviatsis et al. in a series of 108 elderly patients compared with 240 young patients [25].

Despite the higher rate of postoperative morbidities in elderly patients, many studies have shown an improvement in neurological status postoperatively [22, 24]. Zhao et al. demonstrated in their series of 115 elderly patients a significantly lower postoperative KPS (mean KPS of 79.6) than in 413 young patients (mean KPS 88.81) [26]. Li et al. showed no differences among elderly and young patients with a KPS of 90 or higher, 82.9 and $81.2 \%$, respectively, in a follow-up of one year after surgery [21]. There are similar results in the series presented by Slot et al. [20]. The young and elderly patients (also subgroups IIa and IIb) in our cohort showed a significant improvement in postoperative KPS compared to preoperative KPS $(\mathrm{p}<0.001)$. However, patients over 80 years old (subgroup IIc) showed deterioration in postoperative KPS compared to the preoperative KPS. The improvement in neurological conditions, even in the elderly, despite the higher rate of postoperative complications, can be explained by the fact that not all postoperative complications lead to persistent neurological disorders. Moreover, there was a further improvement in KPS at the last follow-up in all patients, even in patients over 80 years of age, compared to their postoperative KPS.

The mortality rate after meningioma surgery also varies greatly in the literature, ranging from 0 to $20 \%$ in elderly patients and $0-6 \%$ in young patients [5, 9, 19, 27-29]. Nakamura et al. and Li. et al. reported no death in their elderly and young cohort groups. However, in the cohort study by Nakamura et al., only 21 patients were included in the elderly group, and no patients with an ASA score of 4 or higher were included in the analysis [28]. Li et al. also investigated only patients with low ASA scores (ASA 1 and 2) in their cohort [21]. Brokinkel et al. showed a significant higher mortality rate in their elderly patients (22\%) than in their young patients (6\%). However, they did not see a significant differences of median overall survival in elderly patients after meningioma surgery compared with age- and sex-matched general population in Germany [30]. In our cohort, 21 patients [6 (1.2\%) young and 15 (5.3\%) elderly patients) died in an observation period of 17.4 years. Patients over 80 years old had the highest mortality rate ( 7 patients (17\%)].

\section{Strengths and limitations of the study}

To our Acknowledge, we present here one of the largest series of elderly and young patients with intracranial meningiomas in a single-center. All patient's demographics, tumor and treatment characteristics, all postoperative complications within 30 days, and follow-up data were collected. As a result, it was possible to evaluate all relevant demographic and clinical data.

The limitation of the study is the retrospective study design. Another limitation of the study is that tumor size and brain edema were not determined volumetrically. However, the tow parameters were not primary points of our investigation and most published studies on this issue do not provide any information about tumor and brain edema volume. The volumetric assessment of tumor size and brain edema will be a focus of investigation in the future.

\section{Conclusions}

Our study demonstrates that meningioma surgery is associated with a higher rate of postoperative complications in elderly patients than in young patients. With the exception of patients over 80 years of age, a significant improvement in neurological status postoperatively was found in our cohort. In addition, the KPS at the last follow-up improved in all patients, even in those over 80 years old. Therefore, based on our data, we conclude that all symptomatic patients who have an indication for surgical therapy should be treated. Patients in high risk groups, such as those over 80 years old and those with multiple comorbidities and high operative risk, should be consulted and supervised perioperatively by an experienced team of neurosurgeons and anesthesiologists.

Supplementary Information The online version contains supplementary material available at https://doi.org/10.1007/s11060-021-03832-5.

Author contribution All authors contributed to the study conception and design. Material preparation, data collection and analysis were performed by HA and CB. The first draft of the manuscript was written by $\mathrm{HA}$ and all authors commented on previous versions of the manuscript. All authors read and approved the final manuscript.

Funding Open Access funding enabled and organized by Projekt DEAL. 
Data availability All data relating to this research project are available at the corresponding author can be viewed at any time if desired.

\section{Declarations}

Conflict of interest The authors declare that they have no conflict of interest.

Ethical approval Our study was approved by the local ethics committee (D468/21), and patients provided written informed consent.

Open Access This article is licensed under a Creative Commons Attribution 4.0 International License, which permits use, sharing, adaptation, distribution and reproduction in any medium or format, as long as you give appropriate credit to the original author(s) and the source, provide a link to the Creative Commons licence, and indicate if changes were made. The images or other third party material in this article are included in the article's Creative Commons licence, unless indicated otherwise in a credit line to the material. If material is not included in the article's Creative Commons licence and your intended use is not permitted by statutory regulation or exceeds the permitted use, you will need to obtain permission directly from the copyright holder. To view a copy of this licence, visit http://creativecommons.org/licenses/by/4.0/.

\section{References}

1. Ostrom QT, Patil N, Cioffi G et al (2020) CBTRUS statistical report: primary brain and other central nervous system tumors diagnosed in the United States in 2013-2017. Neuro Oncol 22:1-96

2. Mehdorn HM (2016) Intracranial meningiomas: a 30-year experience and literature review. Adv Tech Stand Neurosurg 43:139-184

3. Claus EB, Bondy ML, Schildkraut JM et al (2005) Epidemiology of intracranial meningioma. Neurosurgery 57:1088-1095

4. Wiemels JL, Wrensch M, Claus EB (2010) Epidemiology and etiology of meningioma. J Neuro Oncol 99:307-314

5. Awad IA, Kalfas I, Hahn JF, Little JR (1989) Intracranial meningiomas in the aged: surgical outcome in the era of computed tomography. Neurosurgery 24:557-560

6. Bateman BT, Pile-Spellman J, Gutin PH, Berman MF (2005) Meningioma resection in the elderly: nationwide inpatient sample, 1998-2002. Neurosurgery 57:866-872

7. Poon MT, Fung LH, Pu JK, Leung GK (2013) Outcome comparison between younger and older patients undergoing intracranial meningioma resections. J Neurooncol 114:219-227

8. Czernicki T (2020) Surgical management of intracranial meningiomas in the elderly: early and long-term outcomes. Clin Interv Aging 15:2439-2451

9. Arienta C, Caroli M, Balbi S (1992) Intracranial meningiomas in patients over 70 years old. Follow-up in operated and unoperated cases. Aging (Milano) 4:29-33

10. Petridis AK, Doukas A, Mahvash M et al (2009) A case of rapidgrowing anaplastic meningiomas. BMJ Case Rep. doi:https://doi. org/10.1136/bcr.05.2009.1862

11. Louis DN, Ohgaki H, Wiestler OD et al (2007) The 2007 WHO classification of tumours of the central nervous system. Acta Neuropathol 114:97-109

12. Louis DN, Perry A, Reifenberger G et al (2016) The 2016 World Health Organization Classification of tumors of the central nervous system: a summary. Acta Neuropathol 131:803-820
13. Saklad M (1941) Grading of patients for surgical procedures. Anesthesiology 2:281-284

14. Karnofsky DA, Abelmann WH, Craver LF, Burchenal JH (1948) The use of the nitrogen mustards in the palliative treatment of carcinoma. With particular reference to bronchogenic carcinoma. Cancer 1:634-656

15. IBM [IBM SPSS Statistics, 2013]. Release 22.0.0.2 for windows. IBM, Armonk

16. Caroli M, Locatelli F, Prada et al (2005) Surgery for intracranial meningiomas in the elderly: a clinical-radiological grading system as a predictor of outcome. J Neurosurg 102:290-294

17. Sacko O, Sesay M, Roux FE et al (2007) Intracranial meningioma surgery in the ninth decade of life. Neurosurgery 61:950-955

18. Yamamoto J, Takahashi M, Idei M et al (2017) Clinical features and surgical management of intracranial meningiomas in the elderly. Oncol Lett 14:909-917

19. Black P, Kathiresan S, Chung W (1998) Meningioma surgery in the elderly: a case-control study assessing morbidity and mortality. Acta Neurochir 140:1013-1017

20. Slot K, Peters J, Vandertop W et al (2018) Meningioma surgery in younger and older adults: patient profile and surgical outcomes. Eur Geriatr Med 9:95-101

21. Li Y, Lu D, Feng D et al (2020) Management of incidental anterior skull base large and giant meningiomas in elderly patients. $\mathrm{J}$ Neurooncol 148:481-488

22. Guo S, Gerganov V, Giordano M et al (2020) Elderly patients with frontobasal and suprasellar meningiomas: safety and efficacy of tumor removal via frontolateral approach. World Neurosurg 135:452-458

23. Amano T, Nakamizo A, Michiwaki Y et al (2018) Surgical outcome in elderly patients with intracranial meningioma. J Clin Neurosci 56:63-66

24. Maurice-Williams RS, Kitchen ND (1992) Intracranial tumours in the elderly: the effect of age on the outcome of first time surgery for meningiomas. Br J Neurosurg 6:131-137

25. Boviatsis E, Bouras T, Kouyialis A et al (2007) Impact of age on complications and outcome in meningioma surgery. Surg Neurol $68: 407-411$

26. Zhao X, Zhao D, Wu Y et al (2018) Meningioma in the elderly: characteristics, prognostic factors, and surgical strategy. J Clin Neurosci 56:143-149

27. Buhl R, Hasan A, Behnke A, Mehdorn HM (2000) Results in the operative treatment of elderly patients with intracranial meningioma. Neurosurg Rev 23:25-29

28. Nakamura M, Roser F, Dormiani M et al (2005) Surgical treatment of cerebellopontine angle meningiomas in elderly patients. Acta Neurochir 147:603-610

29. Patil C, Veeravagu A, Lad S, Boakye M (2010) Craniotomy for resection of meningioma in the elderly: a multicentre, prospective analysis from the national surgical quality improvement program. J Neurol Neurosurg Psychiatry 81:502-505

30. Brokinkel B, Holling M, Spille DC et al (2017) Surgery for meningioma in the elderly and long-term survival: comparison with an age- and sex-matched general population and with younger patients. J Neurosurg 126:1201-1211

Publisher's Note Springer Nature remains neutral with regard to jurisdictional claims in published maps and institutional affiliations. 